\title{
Implementation of Generalized Regression Neural Network to Establish a Relation between Vibration Parameters and Time of Vibration for Welded Joints
}

\author{
J.Kalpana ${ }^{1}$ Dr. S.V.Ramana ${ }^{2}$ P.Govinda Rao ${ }^{3,}$ Dr. V.ChittiBabu ${ }^{4}$ \\ K Santa $\mathrm{RaO}^{5}$ \\ ${ }^{1}$ PG Student, ${ }^{2}$ Professor, ${ }^{3,4}$ Associate Professor, ${ }^{5}$ Assistant Professor Mechanical Engineering Department, \\ GMRIT, Rajam
}

\begin{abstract}
This paper presents implementation of Generalized Regression Neural Network to establish a relation between vibration parameters and properties of vibration welded joints. During the welding of metals along with mechanical vibrations, uniform and finer grain structures can be produced. This increases the toughness and hardness of the metals, because of solidification effects at the weld pool surface. So, physical experiments have been conducted on the homogeneous welded joints by providing vibrations during the welding period. The voltage used to generate the vibration and the time of vibration are used as vibration parameters. Hardness of the welded joint is considered as one of the mechanical properties of the welded joint.
\end{abstract}

Keywords: Vibratory welding, Neural Networks, Hardness

\section{Introduction}

In manufacturing industries, welding is widely used for metal joining process. Metal arc welding is the most flexible fusion welding and one of the most widely used welding process. The welding joints prepared by arc welding process generally offers good strength and hardness properties. The mechanical vibrations into the weld specimen during welding process improve the weld joint properties significantly. The enhancement in the welded joint properties can be altered by varying the vibration parameters.

Though there exist literature describes the phenomenon of improving the welded joint strength properties, the relation between vibration parameters and the weld joint properties has not been established. Hence the present work is aimed to build a relation between vibration parameters and weld joint properties from the experimental data. Generalised Regression Neural Network is used to build the model.

General regression neural network GRNN is a type of supervised network, and has been widely accepted for its excellent ability to train rapidly on sparse data sets. GRNN usually performs better and faster in continuous function approximation.

\section{Related Work}

Hardness is the Resistance of a material to deformation, indentation, or penetration by means such as abrasion, drilling, impact, scratching and/or wears. The relative toughness of the mild steel or base metal is affected by many variables including: the chemical analysis, micro structural constituents, and strength or hardness level and grain size [11].

Heat treatable steels [12] have improved strength along with good properties of toughness and fatigue strength. In situations when tensile strength and the yield strength of structural steels don't satisfy the design requirements, there is a need for heat treatable steels with higher carbon content. The improved strength allows the production of lighter structures, i.e. the usage of thin sheets. The problems that usually occur in welding of steels with higher carbon content are the following: weld cracking, weld metal porosity, high hardening of the weld metal, and cracking of the base material in HAZ [13]. The application of laser welding in industry is constantly increasing. The most important advantages of laser welding over other procedures include: high welding speed, small or no deformations of the welded parts, and high quality of the welded joint. Laser welding of steels with higher carbon content, such as heat-treatable steels has not yet been applied in high-volume production [13].

Arc welding [14] differs regarding the power density and the volume of heat input into the material. High power density in laser welding allows welding with lower specific heat input than in other welding, which results in very high cooling rates [15]. The cooling rates in arc welding are faster than other welding, so that a lower value of maximum hardness in the welded joint is expected. In vibratory welding, stirrer produce a disturbance in weld pool during solidification. After completion of nucleation, the solidification process will continue with nucleus growth. Increasing the growth rate will reduce the grain size of metal. In welding, as the 
heat source interacts with the material, the severity of thermal excursions experienced by the material varies from region to region, resulting in three distinct regions in the weldment [11].

Jijin Xu, Ligong Chen and Chunzhen Ni [4] described about the effects of the vibratory weld conditioning on the residual stress and distortion in multipass girth-butt welded pipes and also discussed about how vibratory weld conditioning reduce the residual hoop stresses at the outer surface and the radial distortion significantly. The improvement of welded structure's properties fatigue damage resistance, stress corrosion cracking and fracture resistance due to vibratory weld conditioning is also well discussed.

Lakshminarayanan A.K. and Balasubramanian. V [5] described about improvement in tensile properties of 409M ferritic stainless steel welded joints in comparison with base metal. Ductility and impact toughness of welded joints also tested for the welded joints. Lu Qinghua, Chen Ligong and Ni Chunzhen [6] discussed about the applications of vibration during submerged arc multi-pass welding to improve welded valve quality. The reduction in residual deformation and stress due to vibratory weld conditioning is discussed. The enhancement of the impact property in the weld metal due to vibratory weld conditioning is described.

Munsi A S M Y, Waddell A J and Walker C A[7] discussed about the effect of vibratory stress on the welding microstructure and residual stress distribution of steel welded joints. The 25 percent improvement in hardness of weld joint is also discussed. Shigeru Aoki, Tadashi Nishimura and Tetsumaro Hiroi [8] discussed about a method for reducing the residual stress using random vibrations during welding. The residual stress in the quenched butt-welded joint is measure by paralleled beam X-ray diffractometer with scintillation counter.

Tewari S P and Shanker A.[9] described about improvements on yield strength, ultimate tensile strength and breaking strength on shielded metal arc welded joints due to vibratory conditions like longitudinal vibration and frequency. The drop in percentage of elongation due to the vibratory conditions is discussed. Weglowska. A, and Pietras A[10] described the influence of the welding parameters on the mechanical properties of vibration welded joints such are tensile properties and microscopic behaviour of dissimilar grades of nylons.

Dirk Tomandl and Andreas Schober[1] discussed about modified general regression neural network, which can be applied for common practical problems. Supervised training algorithms are proposed for training of neural network. Donald F. Specht[2] described about a one pass learning algorithm with well parallel structure named as the general regression neural network (GRNN), which can train sparse data in a multidimensional measurement space. The general regression neural network provides estimates of continuous variable and converges to the underlying linear or non linear regression surface. The parallel network form is superior in learning the dynamics of a model and also for prediction. Any non linear regression problem can be modelled with this algorithm. Hsien-Yu Tseng[3] described about implementing the general regression neural network to create approximate models to relate the spot welding parameters, weld joint strength and power required to prepare the weld joint. And implementation of optimisation algorithm on the neural approximation model to find out the economic design.

In the present study, welding is performed along with the vibrations for improving the mechanical properties of the base material. Physical experiments have been conducted on the homogeneous welded joints by providing vibrations during the welding period. Thereby, implementation of Generalized Regression Neural Network to establish a relation between vibration parameters and properties of vibration welded joints.

\section{Vibration equipment setup}

\section{Experimental work}

A platform to place the specimen is equipped with four springs along each the corner. The vibration platform is prepared by attaching a vibro motor to the vibration table set. A dimmer stat, voltmeter and ammeter are attached to the vibro motor to generate the vibrations. Fig.1a and Fig $1 \mathrm{~b}$ show the experimental setup.

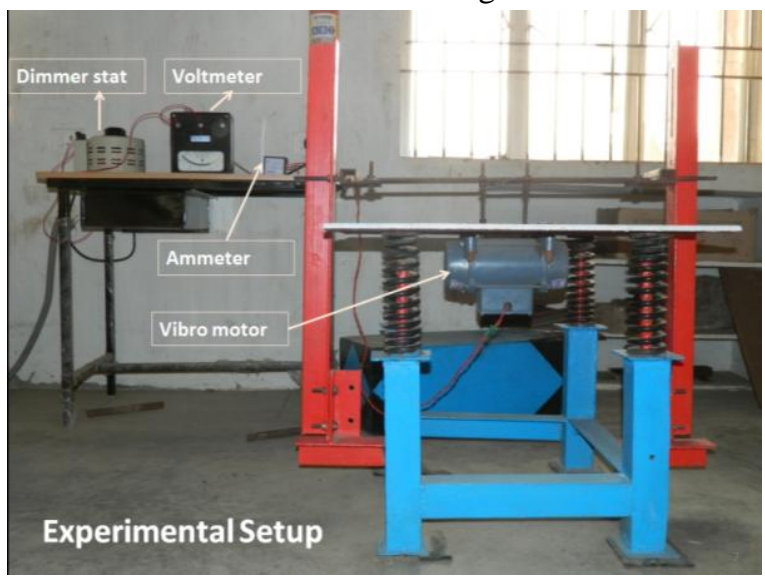

Fig.1a Vibration platform equipment setup

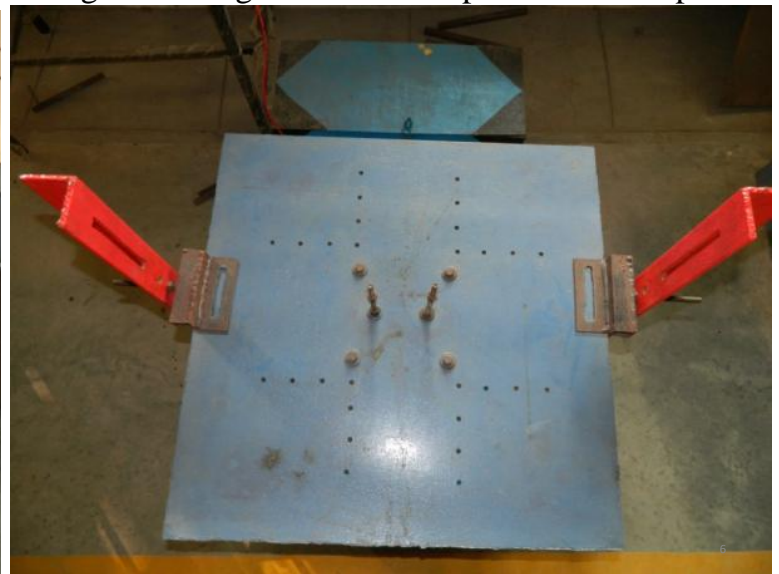

Fig.1b Vibration platform surface plate

wWw.iosrjournals.org

$37 \mid$ Page 


\section{Vibratory Setup for Welding}

With an aim of improving the mechanical properties of weld joints through inducing of favourable changes in the weld microstructures, an auxiliary vibratory set up capable of inducing mechanical vibrations into the weld pool during manual metal arc welding is designed and developed. Different frequencies and with different amplitude are applied along the weld length, just trailing behind the welding arc so that weld pool could be mechanically stirred in order to induce favourable micro structural effects. This setup produces the required frequency with the amplitude in terms of voltages.

\section{Weld joint Specimens Preparation}

Mild Steel of $5 \mathrm{~mm}$. thickness is used in the current investigation, it is composed of (in weight percentage) $0.9 \%$ Carbon $(\mathrm{C}), 7.5-10.0 \%$ manganese $(\mathrm{Mn}), 1.00 \%$ Silicon $(\mathrm{Si}), 17.0-19.0 \%$ Chromium $(\mathrm{Cr})$, 4.0-6.0\% Nickel (Ni), 0.06\% Phosphorus (P), 0.03\% Sulphur (S), and the base metal Iron (Fe).

Steel plates are placed on the vibration platform and power is supplied to the vibration equipment. Specimen welding is represented in Fig. 2

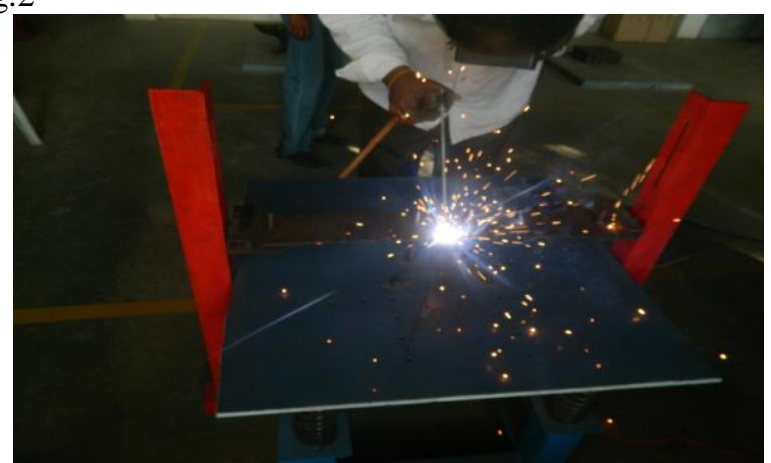

Fig.2. Welding the specimen using vibrations

The joints prepared by using arc welding using vibration equipment is represented in Fig.3

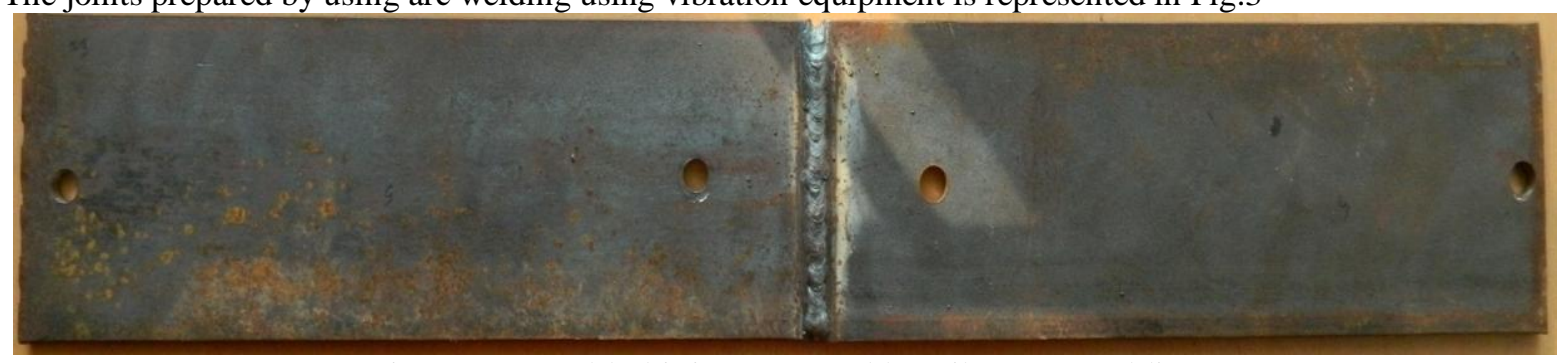

Fig.3. Butt welded joint prepared by vibratory welding

\section{Measurement of Hardness}

The Rockwell Hardness test is probably is the most widely used method of hardness testing. Rockwell testers use much smaller penetrators and loads than does the Brinell tester. Hardness is measured at the center of the weld bead for different welded specimens prepared under different voltages of vibrometer and times of vibration. Example of one specimen is shown in Fig.4.

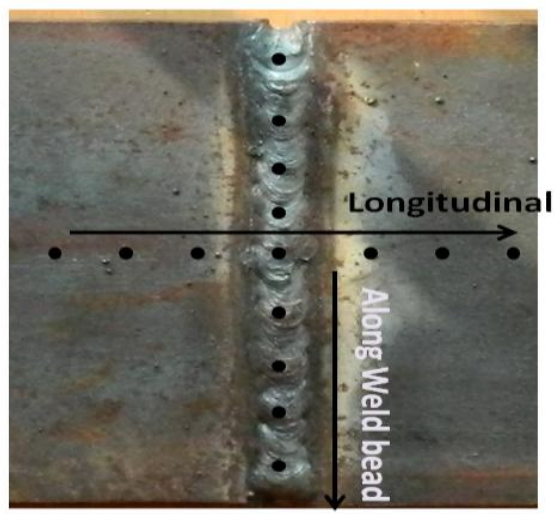

Fig.4. Locations for hardness testing on the welded joint 
For different combinations of voltage and time of vibration, weld specimens are prepared and tested for hardness on both of the sides. The experiments are carried out at 95 different combinations and the results are tabulated in Table.1.

Table.1 Welded joints hardness values experimental data

\begin{tabular}{|c|c|c|c|c|c|c|c|c|c|}
\hline \multirow{3}{*}{ Expt. No. } & $\mathbf{x 1}$ & \begin{tabular}{|l|}
$\mathrm{X} 2$ \\
\end{tabular} & Y1 & $Y 2$ & \multirow{3}{*}{ Expt. No. } & $\mathbf{x 1}$ & \multirow{3}{*}{\begin{tabular}{|c|}
$\mathrm{X} 2$ \\
TIME OF \\
YIBRA TION \\
[seconds] \\
\end{tabular}} & \multirow[b]{2}{*}{$\begin{array}{c}\text { HARD } \\
\text { NESS_1 }\end{array}$} & \multirow{2}{*}{ 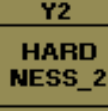 } \\
\hline & \multirow[t]{2}{*}{ VOLTAGE [Y] } & \multirow[t]{2}{*}{$\begin{array}{c}\text { TIME OF } \\
\text { VIBRA TION } \\
\text { [seconds] }\end{array}$} & \multirow[t]{2}{*}{$\begin{array}{c}\text { HARD } \\
\text { NESS_1 }\end{array}$} & \multirow[t]{2}{*}{$\begin{array}{c}\text { HARD } \\
\text { NESS_2 }\end{array}$} & & \multirow[t]{2}{*}{ VOLTAGE [Y] } & & & \\
\hline & & & & & & & & Ist side & 2nd side \\
\hline 1 & 50 & 60 & 67 & 84 & 49 & 140 & 120 & 75 & 83 \\
\hline 2 & 50 & 80 & 71 & 86 & 50 & 140 & 140 & 77 & 84 \\
\hline 3 & 50 & 100 & 76 & 88 & 51 & 150 & 60 & 58 & 77 \\
\hline 4 & 50 & 120 & 83 & 91 & 52 & 150 & 80 & 65 & 79 \\
\hline 5 & 50 & 140 & 87 & 93 & 53 & 150 & 100 & 66 & 80 \\
\hline 6 & 60 & 60 & 66 & 83 & 54 & 150 & 120 & 75 & 82 \\
\hline 7 & 60 & 80 & 70 & 85 & 55 & 150 & 140 & 76 & 83 \\
\hline 8 & 60 & 100 & 75 & 87 & 56 & 160 & 60 & 57 & 76 \\
\hline 9 & 60 & 120 & 82 & 90 & 57 & 160 & 80 & 64 & 78 \\
\hline 10 & 60 & 140 & 86 & 92 & 58 & 160 & 100 & 65 & 80 \\
\hline 11 & 70 & 60 & 65 & 83 & 59 & 160 & 120 & 73 & 81 \\
\hline 12 & 70 & 80 & 69 & 84 & 60 & 160 & 140 & 75 & 82 \\
\hline 13 & 70 & 100 & 73 & 86 & 61 & 170 & 60 & 57 & 75 \\
\hline 14 & 70 & 120 & 81 & 89 & 62 & 170 & 80 & 62 & 77 \\
\hline 15 & 70 & 140 & 85 & 91 & 63 & 170 & 100 & 64 & 79 \\
\hline 16 & 80 & 60 & 64 & 82 & 64 & 170 & 120 & 72 & 80 \\
\hline 17 & 80 & 80 & 68 & 83 & 65 & 170 & 140 & 74 & 81 \\
\hline 18 & 80 & 100 & 72 & 85 & 66 & 180 & 60 & 56 & 74 \\
\hline 19 & 80 & 120 & 80 & 88 & 67 & 180 & 80 & 61 & 77 \\
\hline 20 & 80 & 140 & 83 & 90 & 68 & 180 & 100 & 63 & 78 \\
\hline 21 & 90 & 60 & 63 & 81 & 69 & 180 & 120 & 71 & 79 \\
\hline 22 & 90 & 80 & 67 & 83 & 70 & 180 & 140 & 73 & 80 \\
\hline 23 & 90 & 100 & 70 & 85 & 71 & 190 & 60 & 54 & 74 \\
\hline 24 & 90 & 120 & 79 & 87 & 72 & 190 & 80 & 61 & 76 \\
\hline 25 & 90 & 140 & 82 & 89 & 73 & 190 & 100 & 62 & 77 \\
\hline 26 & 100 & 60 & 61 & 81 & 74 & 190 & 120 & 70 & 78 \\
\hline 27 & 100 & 80 & 67 & 82 & 75 & 190 & 140 & 72 & 79 \\
\hline 28 & 100 & 100 & 70 & 84 & 76 & 200 & 60 & 53 & 72 \\
\hline 29 & 100 & 120 & 78 & 86 & 77 & 200 & 80 & 60 & 74 \\
\hline 30 & 100 & 140 & 81 & 88 & 78 & 200 & 100 & 62 & 76 \\
\hline 31 & 110 & 60 & 61 & 80 & 79 & 200 & 120 & 68 & 77 \\
\hline 32 & 110 & 80 & 67 & 81 & 80 & 200 & 140 & 71 & 78 \\
\hline 33 & 110 & 100 & 69 & 83 & 81 & 210 & 60 & 52 & 71 \\
\hline 34 & 110 & 120 & 77 & 85 & 82 & 210 & 80 & 60 & 73 \\
\hline 35 & 110 & 140 & 80 & 87 & 83 & 210 & 100 & 61 & 75 \\
\hline 36 & 120 & 60 & 60 & 79 & 84 & 210 & 120 & 67 & 76 \\
\hline 37 & 120 & 80 & 67 & 81 & 85 & 210 & 140 & 70 & 77 \\
\hline 38 & 120 & 100 & 68 & 83 & 86 & 220 & 60 & 51 & 70 \\
\hline 39 & 120 & 120 & 76 & 84 & 87 & 220 & 80 & 59 & 72 \\
\hline 40 & 120 & 140 & 79 & 86 & 88 & 220 & 100 & 60 & 74 \\
\hline 41 & 130 & 60 & 60 & 78 & 89 & 220 & 120 & 65 & 75 \\
\hline 42 & 130 & 80 & 66 & 80 & 90 & 220 & 140 & 69 & 76 \\
\hline 43 & 130 & 100 & 67 & 82 & 91 & 230 & 60 & 51 & 70 \\
\hline 44 & 130 & 120 & 76 & 84 & 92 & 230 & 80 & 57 & 71 \\
\hline 45 & 130 & 140 & 78 & 85 & 93 & 230 & 100 & 59 & 73 \\
\hline 46 & 140 & 60 & 59 & 78 & 94 & 230 & 120 & 63 & 74 \\
\hline 47 & 140 & 80 & 65 & 80 & 95 & 230 & 140 & 67 & 75 \\
\hline 48 & 140 & 100 & 67 & 81 & & & & & \\
\hline
\end{tabular}

\section{GRNN Model Preparation}

For the present work, the experimental data is used to create a GRNN model, The voltage and time of vibration are used as input parameters $(\mathrm{X} 1, \mathrm{X} 2)$ and the hardness values on both the sides $(\mathrm{Y} 1, \mathrm{Y} 2)$ are considered as output parameters. GRNN estimate the hardness values for any combination of time of vibration and voltage values.

From the weld joint experimental data 76 experimental data is considered randomly to create the GRNN model.

$$
\hat{Y}(X)=\frac{\sum_{i=1}^{n} Y_{i} \exp \left(-D_{i}^{2} / 2 \sigma^{2}\right)}{\sum_{i=1}^{n} \exp \left(-D_{i}^{2} / 2 \sigma^{2}\right)}
$$


Where $(\mathrm{Xi}, \mathrm{Yi})$ is a sample of $(\mathrm{X}, \mathrm{Y})$ input parameters, $\mathrm{D}^{2}{ }_{\mathrm{i}}=\left(\mathrm{X}-\mathrm{X}_{\mathrm{i}}\right)^{\mathrm{T}}\left(\mathrm{X}-\mathrm{X}_{\mathrm{i}}\right)$, and $\sigma$ is the smoothing parameter. As a pre-processing step in GRNN, the scaling factors are calculated from the standard deviation values of input parameters presented in Table.2.

\begin{tabular}{|l|c|c|}
\hline & $\mathbf{X 1}$ & $\mathbf{X 2}$ \\
\hline STANDARD DEVIATIONS & 55.50659831 & 28.839544 \\
\hline SCALING FACTORS & 0.519569653 & 1 \\
\hline
\end{tabular}

Table. 2 Scaling factors and Standard deviation values for input parameters.

A smoothing parameter $\sigma$ is determined for the computation purpose. By trial and error method two different values are chosen for (Y1 and Y2) two hardness values. In the equation (1), $2 \sigma^{2}$ for Hardness_1 is 9 and for Hardness_2 is 25 .

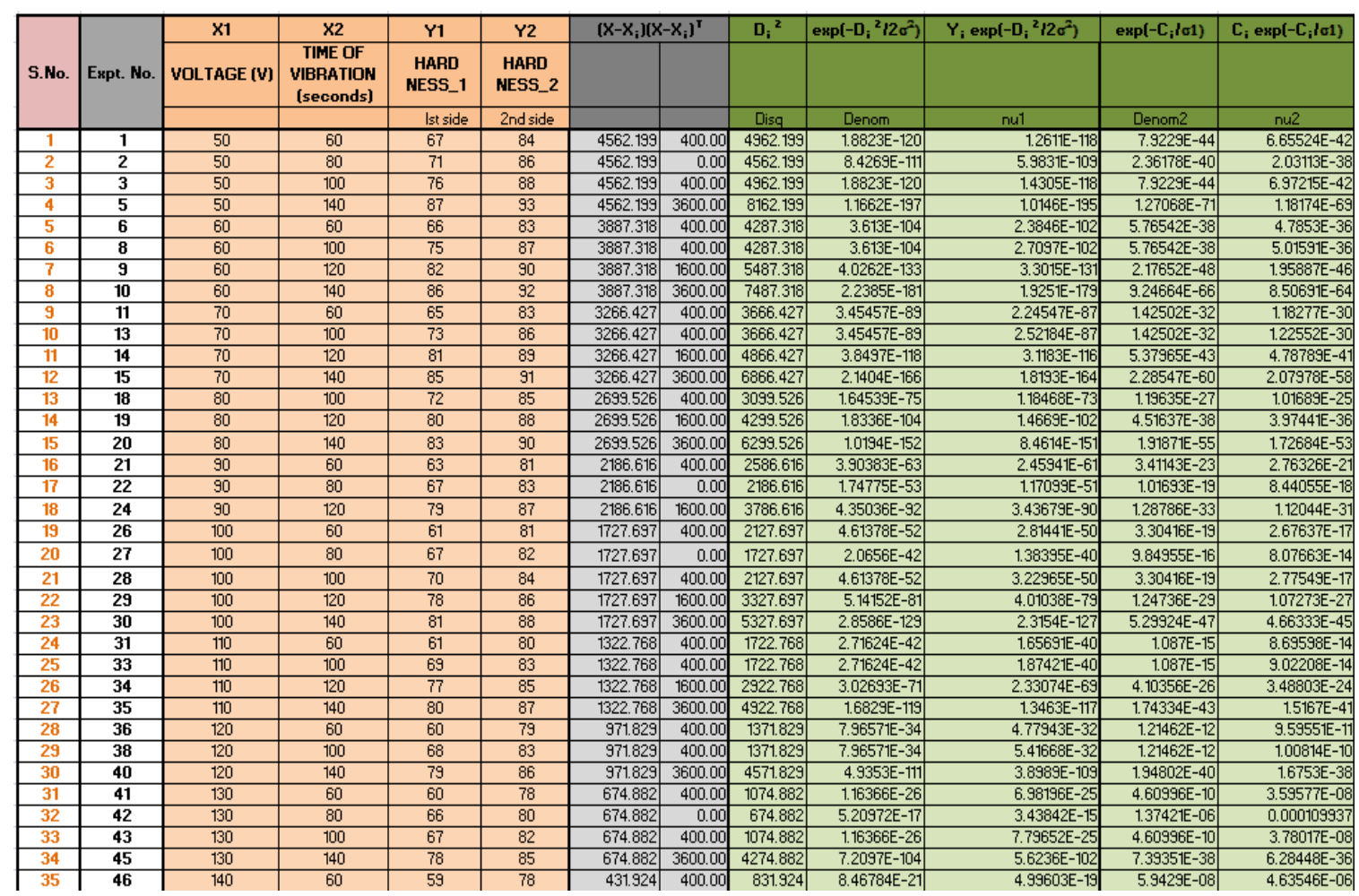

Table.3 GRNN model for weld joint database

\section{GRNN Model Calibration}

The GRNN model created for 76 random experiment values are tested for two different sets of used experimental data and un-used experimental data. The calibrated data for the first 15 sets are represented in Table.4. The deviations in the GRNN computed values from the used experimental values are also captured in Table.4. The deviations are plotted in Fig.5.

\begin{tabular}{|c|c|c|c|c|c|c|c|c|c|}
\hline \multirow{3}{*}{ S.No. } & \multirow{3}{*}{ Expt. No. } & $\mathrm{x} 1$ & \multirow{3}{*}{$\begin{array}{c}\text { X2 } \\
\text { TIME OF } \\
\text { VIBRATION } \\
\text { (seconds) }\end{array}$} & \multirow{3}{*}{$\begin{array}{c}\text { Y1 } \\
\text { HARD } \\
\text { NESS_1 } \\
\text { Ist side } \\
\end{array}$} & \multirow{3}{*}{$\begin{array}{c}\text { Y2 } \\
\text { HARD } \\
\text { NESS_2 } \\
\text { 2nd side } \\
\end{array}$} & \multirow{2}{*}{\multicolumn{2}{|c|}{$\begin{array}{l}\text { HARD NESS VALUES } \\
\text { FROM GRNN MODEL }\end{array}$}} & \multirow{2}{*}{\multicolumn{2}{|c|}{ Error percentage }} \\
\hline & & \multirow[t]{2}{*}{ VOLTAGE (V) } & & & & & & & \\
\hline & & & & & & Ist side & 2nd side & & \\
\hline 1 & 1 & 50 & 60 & 67 & 84 & 66.81385563 & 83.58907244 & 0.277827422 & 0.48919948 \\
\hline 2 & 2 & 50 & 80 & 71 & 86 & 71 & 85.99895439 & $-2.77412 \mathrm{E}-11$ & 0.001215823 \\
\hline 3 & 3 & 50 & 100 & 76 & 88 & 75.81182686 & 87.50948845 & 0.24759624 & 0.557399488 \\
\hline 4 & 5 & 50 & 140 & 87 & 93 & 86.81385135 & 92.50909043 & 0.213963965 & 0.527859755 \\
\hline 5 & 6 & 60 & 60 & 66 & 83 & 65.99999715 & 83.26107865 & $4.31859 \mathrm{E}-06$ & -0.31455259 \\
\hline 6 & 8 & 60 & 100 & 75 & 87 & 74.84081753 & 86.89918826 & 0.212243298 & 0.115875568 \\
\hline 7 & 9 & 60 & 120 & 82 & 90 & 81.81385247 & 89.50900121 & 0.227009182 & 0.545554212 \\
\hline 8 & 10 & 60 & 140 & 86 & 92 & 85.9948621 & 91.89793746 & 0.0059743 & 0.110937545 \\
\hline 9 & 11 & 70 & 60 & 65 & 83 & 65.1817228 & 82.92791523 & -0.279573535 & 0.086849125 \\
\hline 10 & 13 & 70 & 100 & 73 & 86 & 73.15917948 & 86.09467347 & -0.218054082 & -0.110085428 \\
\hline 11 & 14 & 70 & 120 & 81 & 89 & 80.99657189 & 88.88851775 & 0.004232232 & 0.125260961 \\
\hline 12 & 15 & 70 & 140 & 85 & 91 & 84.84937704 & 91.08958885 & 0.177203487 & -0.098449289 \\
\hline 13 & 18 & 80 & 100 & 72 & 85 & 72.18374859 & 85.3865415 & -0.255206377 & -0.454754708 \\
\hline 14 & 19 & 80 & 120 & 80 & 88 & 79.99999716 & 87.99024957 & $3.55176 \mathrm{E}-06$ & 0.011080031 \\
\hline 15 & 20 & 80 & 140 & 83 & 90 & 83.36547566 & 90.3171882 & -0.440332119 & -0.352431329 \\
\hline
\end{tabular}

Table.4. Calibrated data for used experimental data 


\section{CALIBRATION PLOT FOR USED WELD DATA}

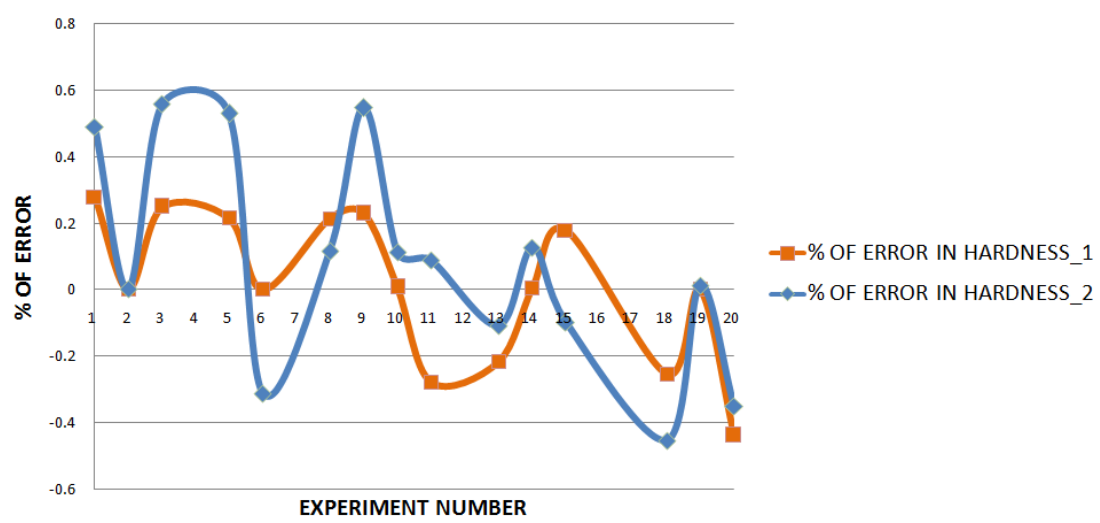

Fig.5 Graphical representation of error percentage

The un-used experimental data for creation of GRNN model is also calibrated for 15 sets are represented in Table.5. The deviations in the GRNN computed values from the un-used experimental values are also captured in Table.5. The deviations are plotted in Fig.6.

\begin{tabular}{|c|c|c|c|c|c|c|c|c|c|}
\hline \multirow{3}{*}{ S.No. } & \multirow{3}{*}{ Expt. No. } & \multirow{3}{*}{$\begin{array}{c}\mathrm{X} 1 \\
\text { VOLTAGE (V) }\end{array}$} & \multirow{3}{*}{$\begin{array}{c}\text { X2 } \\
\text { TIME OF }\end{array}$} & \multirow{3}{*}{$\begin{array}{c}\text { Y1 } \\
\text { HARD } \\
\text { Ist side }\end{array}$} & \multirow{3}{*}{$\begin{array}{c}\text { Y2 } \\
\text { HARD } \\
\text { 2nd side }\end{array}$} & \multirow{2}{*}{\multicolumn{2}{|c|}{$\begin{array}{l}\text { HARD NESS VALUES } \\
\text { FROM GRNN MODEL }\end{array}$}} & \multirow{3}{*}{\multicolumn{2}{|c|}{ Error percentage }} \\
\hline & & & & & & & & & \\
\hline & & & & & & \begin{tabular}{|l|l} 
Ist side \\
\end{tabular} & 2nd side & & \\
\hline 1 & 4 & 50 & 120 & 83 & 91 & 81.98899236 & 89.81419765 & 1.218081494 & 1.303079511 \\
\hline 2 & 7 & 60 & 80 & 70 & 85 & 70.99997537 & 85.957298 & -1.428536242 & -1.126232944 \\
\hline 3 & 12 & 70 & 80 & 69 & 84 & 68.9994464 & \begin{tabular}{|l|l|}
84.4202513 \\
\end{tabular} & 0.000802318 & -0.500299164 \\
\hline 4 & 16 & 80 & 60 & 64 & 82 & 63.99450227 & 81.99976558 & 0.008590202 & 0.000285874 \\
\hline 5 & 17 & 80 & 80 & 68 & 83 & 67.00002436 & 82.87113261 & 1.470552408 & 0.155261915 \\
\hline 6 & 23 & 90 & 100 & 70 & 85 & 71.00000305 & 84.50633956 & -1.428575783 & 0.580776986 \\
\hline 7 & 25 & 90 & 140 & 82 & 89 & 82.00550077 & 88.99886402 & -0.006708259 & 0.001276387 \\
\hline 8 & 32 & 110 & 80 & 67 & 81 & 66.98911207 & 81.83943967 & 0.016250636 & -1.036345275 \\
\hline 9 & 37 & 120 & 80 & 67 & 81 & 65.99999999 & 80.29764779 & 1.492537322 & 0.867101495 \\
\hline 10 & 39 & 120 & 120 & 76 & 84 & 76.98912418 & 84.85039784 & -1.301479186 & -1.012378377 \\
\hline 11 & 44 & 130 & 120 & 76 & 84 & 755.02175763 & 83.14910871 & \begin{tabular}{|l|}
1.28716101 \\
\end{tabular} & 1.012965827 \\
\hline 12 & 50 & 140 & 140 & 77 & 84 & 77.97823633 & 84.70115159 & -1.270436796 & -0.834704279 \\
\hline 13 & 55 & 150 & 140 & 76 & 83 & 75.02176366 & 82.29695192 & 1.287153075 & 0.847045874 \\
\hline 14 & 61 & 170 & 60 & 57 & 75 & 56.49449923 & 75.08256612 & 0.886843457 & -0.11008816 \\
\hline 15 & 67 & 180 & 80 & 61 & 77 & 61.50550382 & $\begin{array}{l}76.41247563 \\
\end{array}$ & -0.828694781 & 0.763018658 \\
\hline
\end{tabular}

Table.4. Calibrated data for un-used experimental data CALIBRATION PLOT FOR UN-USED WELD DATA

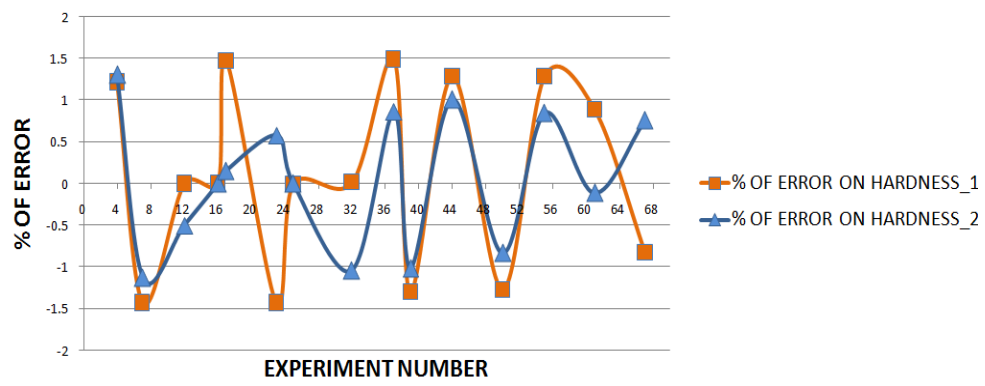

Fig.5 Graphical representation of error percentage for non used experimental data

\section{Conclusions}

In the present study, welding is performed along with the vibrations for improving the mechanical properties of the base material. The vibratory welded joints properties, such are hardness values along and across the weldbeed are varying in accordance with vibration time and voltage supplied to generate the vibration. Due to the non linear behaviour relation between the vibration weld parameters and the welded joint hardness properties, GRNN model is created. The proposed GRNN model is highly superior which is computing the values with $99 \%$ accuracy for the used experimental values with \pm 0.5 error and $97 \%$ accurate for the un used experimental values with \pm 1.5 . 


\section{References}

[1]. Dirk Tomandl and Andreas Schober (2001) A Modified General Regression Neural Network (MGRNN) with new, efficient training algorithms as a robust 'black box'- tool for data analysis. Journal of Neural Networks, 14, pp1023-1034.

[2]. Donald F.Specht (1991) A General Regression Neural Network, IEEE Transactions on Neural Networks, Vol.2, No.6,pp568-576.

[3]. Hsien-Yu Tseng(2006), Welding parameters optimization for economic design using neural approximation and genetic algorithm, Int. J. Adv. Manufacturing Technology vol27:pp897-901.

[4]. Jijin Xu, Ligong Chen and Chunzhen Ni (2006) Effect of vibratory weld conditioning on the residual stresses and distortion in multipass girth-butt welded pipes, International Journal of Pressure vessels and piping 84,pp298-303.

[5]. Lakshminarayanan A.K. and Balasubramanian. V(2010) An assessment of microstructure hardness, tensile and impact strength of friction stir welded ferritic stainless steel joints, 31, pp 4592-4600.

[6]. Lu Qinghua, Chen Ligong and Ni Chunzhen (2006) Improving welded valve quality by vibratory weld conditioning, Materials Science and Engineering A 457, pp246-253.

[7]. Munsi, A.S.M.Y. and Waddell, A.J. and Walker, C.A. (2001) The effect of vibratory stress on the welding microstructure and residual stress distribution. Proceedings of the Institution of Mechanical Engineers, Journal of Materials: Design and Applications, 215 (2). pp. 99-111.

[8]. Shigeru Aoki, Tadashi Nishimura and Tetsumaro Hiroi (2005) Reduction method for residual stress of welded joint using random vibration, Nuclear Engineering Design, 235,pp1441-1445.

[9]. Tewari, S. P. and Shanker (1993), A. Effect of longitudinal vibration on the mechanical properties of mild steel weldments. Proc. Instn Mech. Engrs, Part B, Journal of Engineering Manufacture, 207(B3), 173-177.

[10]. Weglowska. A. and Pietras. A. (2012), Influence of the welding parameters on the structure and mechanical properties of vibration welded joints of dissimilar grades of nylons. Archives of civil and mechanical engineering 12, pp198-204.

[11]. Nagy, M. J., Jr. and D. M. Kelman, Application of ultrasonic vibrations during solidification of vacuum-arc melted Ingots. METALS ENGINEERING QUARTERLY 1:72-82, Nov 1961.

[12]. H. Kaufmann, Laser welding - will it have any significant impact on welding ?, Svetsaren, Vol. 56, 2-3, pp. 73-75, 2001.

[13]. T. Webber, High power CW Nd:YAG laser welding of high carbon steel with pre- and post-weld heat treatment, Proc. of, 5th CISFFEL International Conference, La Baule, June 1993.

[14]. J.K. Larsson, Laser welding: A mature process technology with various application fields, Svetsaren, 1-2, pp.43-50, 1999.

[15]. M. Naeem, YAG laser welding of thin sheet, Welding \& Metal Fabrication, Vol. 68, No. 6, pp.6-10, June, 2000. 